\title{
Social Competence Treatment after Traumatic Brain Injury: A Multicenter, Randomized, Controlled Trial of Interactive Group Treatment versus Non-Interactive Treatment
}

\author{
Authors: \\ Cynthia Harrison-Felix, $\mathrm{PhD}_{\mathrm{a}} \mathrm{b}$ \\ Jody K. Newman, MA, CCC-SLP a \\ Lenore Hawley, MSSW, LCSW, CBIST a \\ Clare Morey, MA, CCC-SLP a \\ Jessica M. Ketchum, PhD a, b \\ William C. Walker, MD c, d \\ Kathleen R. Bell, MD e \\ Scott R Millis, PhD, ABPP-CN f, g \\ Cynthia Braden, MA, CCC-SLP a \\ James Malec, PhD, ABPP-CN h, i \\ Flora M. Hammond, MD h, i \\ CB Eagye, MS a \\ Laura Howe, JD, PhD j
}

a Craig Hospital, Englewood CO, USA; b Traumatic Brain Injury Model Systems National Data and

Statistical Center, Englewood CO, USA; c Hunter Holmes McGuire Veterans Affairs Medical

Center, Virginia, d Department of Physical Medicine and Rehabilitation, Virginia Commonwealth

University; University of Washington (currently at University of Texan Southeastern Medical

Center e ; f Rehabilitation Institute of Michigan, g Wayne State University School of Medicine; $h$

Rehabilitation Hospital of Indiana, i Department of Physical Medicine and Rehabilitation; Indiana

University School of Medicine; j Polytrauma Rehabilitation Center

VA Palo Alto Health Care System

This is the author's manuscript of the article published in final edited form as:

Harrison-Felix, C., Newman, J. K., Hawley, L., Morey, C., Ketchum, J. M., Walker, W. C., ... Howe, L. (2018). Social Competence Treatment after Traumatic Brain Injury: A Multicenter, Randomized, Controlled Trial of Interactive Group Treatment versus Non-Interactive Treatment. Archives of Physical Medicine and Rehabilitation. 
Disclosure of Interest: There are no conflicts of interest to report.

Acknowledgement of financial support: This study was funded by the United States Department of Defense, Award Number W81XWH-11-1-0635; PT100068. Clinical Trial Registration number: NCT01465269

The authors thank Laura Beck, BA and Angela Philippus, BA for their assistance throughout the grant. The authors also thank the individuals who participated in the study and their families. 
Social Competence Treatment after TBI

\section{Social Competence Treatment after Traumatic Brain Injury: A Multicenter, Randomized, Controlled Trial of Interactive Group Treatment versus Non-Interactive Treatment}

\section{ABSTRACT}

Objective: To evaluate the effectiveness of a replicable group treatment program for improving social competence after traumatic brain injury (TBI). Design: Multicenter randomized controlled trial comparing two methods of conducting a social competency skills program, an interactive group format versus a classroom lecture. Setting: Community and Veteran rehabilitation centers. Participants: 179 civilian, military, and veteran adults with TBI and social competence difficulties, at least 6 months post-injury. Experimental Intervention: Thirteen weekly group interactive sessions (1.5 hours) with structured and facilitated group interactions to improve social competence. Alternative (Control) Intervention: Thirteen traditional classroom sessions using the same curriculum with brief supplemental individual sessions but without structured group interaction. Primary Outcome Measure: Profile of Pragmatic Impairment in Communication (PPIC), an objective behavioral rating of social communication impairments following TBI. Secondary Outcomes: LaTrobe Communication Questionnaire (LCQ), Goal Attainment Scale (GAS), Satisfaction with Life Scale (SWLS), Post-Traumatic Stress Disorder Checklist - (PCL-C), Brief Symptom Inventory 18 (BSI-18), Scale of Perceived Social Self Efficacy (PSSE). Results: Social competence goals (GAS) were achieved and maintained for most participants regardless of treatment method. Significant improvements in the primary outcome (PPIC) and two of the secondary outcomes (LCQ and BSI) were seen immediately posttreatment and at 3 months post-treatment in the AT arm only, however these improvements 
Social Competence Treatment after TBI

24 were not significantly different between the GIST and AT arms. Similar trends were observed

25 for PSSE and PCL-C. Conclusions: Social competence skills improved for persons with TBI in both

26 treatment conditions. The group interactive format was not found to be a superior method of

27 treatment delivery in this study.

28 Key Words: Social skills, brain injuries, treatment

29 Abbreviations:

30 AT Alternative Treatment

31 BSI-18 Brief Symptom Inventory 18

32 GAS Goal Attainment Scaling

33 GIST Group Interactive Structured Treatment

34 LCQ LaTrobe Communication Questionnaire

35 OSU-TBI-ID Ohio State University Traumatic Brain Injury Identification

36 PCL - C Post Traumatic Stress Disorder Check List-Civilian Version

37 PPIC Profile of Pragmatic Impairment in Communication

PSSE Scale of Perceived Social Self-Efficacy

PTSD Post Traumatic Stress Disorder

RAVLT Rey Auditory Verbal Learning Test

41

SCSQ Social Communication Skills Questionnaire 
Social Competence Treatment after TBI

42

43

44

45

46

47

48

49

50

51

52

53

54

55

56

57

58

59

60

61

SWLS Satisfaction with Life Scale

TBI Traumatic Brain Injury

TMT Trail Making Test

VA Veteran's Affairs

Social competence encompasses the cognitive, emotional, and communication skills needed to interact successfully, as well as knowing how to apply those skills in a variety of social situations.[1-3] Impairments in social competence and interpersonal skills are among the most prevalent and persistent sequelae after traumatic brain injury (TBI) and often present a major barrier to an individual returning to a satisfying and productive life.[4] Difficulties with social competence may arise due to a combination of factors including the extent of the neurological injury, pre-injury social functioning, psychological reaction to the injury, social context, family dynamics, co-existing pain, and fatigue. Regardless of the etiology, persisting social competence issues after TBI may present a major obstacle to community reintegration.

Social competence impairments may occur across a wide range of areas, including starting or ending conversations; staying focused on a social interaction; maintaining social boundaries; taking turns; initiating social interactions; and resolving conflicts. Deficits in interpersonal skills have been found to be the most frequent cause of job loss for individuals post-TBI [5]. Ezrachi et al. [6] found that interpersonal factors, rather than work skills, lead to the most problems in sustaining employment. Wehman and colleagues report that individuals with severe TBI, who 
Social Competence Treatment after TBI

62

63

64

65

66

67

68

69

70

71

72

73

74

75

76

77

78

79

80

81

82

83

worked in positions that required numerous social interactions, had more difficulty obtaining and maintaining jobs[7]. Loneliness and social isolation have also been commonly cited postTBI[8] $[9,10]$. Individuals with TBI commonly have difficulty adapting their social skills to new social situations.[11] Problems with social perception, and misunderstanding the intentions, inferences, and emotions of conversation partners are also often reported.[12] In general, social interactions with individuals with TBI have been characterized as effortful and unrewarding [11].

Historically, impairments in social skills have been addressed in group treatment, incorporating group feedback, practice and interaction.[13-15] Social skills treatment after TBI often emphasizes enhancing specific social, behavioral and communication skills and adapting those skills in various social contexts, as well as increasing social self-awareness, self-efficacy and confidence.

Published research regarding social skills and TBI specific to the military population is limited.

The recent and ongoing military conflicts have resulted in increased difficulties with adjusting to post-deployment life among veterans and service members. [16] Military personnel with TBI who seek treatment for social skills problems report a lack of interest in others, difficulty resolving interpersonal conflicts, and difficulty interacting with family members[3]. In addition, Hoge and colleagues found that $44 \%$ of soldiers with mild TBI (MTBI) and associated loss of consciousness also met criteria for post-traumatic stress disorder (PTSD)[17]. Hoge, et al. also noted a strong association between MTBI, PTSD, and other health symptoms in combat veterans. These comorbid mental health problems may further impact social functioning within the military TBI population. 
Social Competence Treatment after TBI

84

Currently, there is no gold standard of treatment for social competence problems after TBI and few evidence-based social competence TBI treatment programs.[18, 19] Group Interactive Structured Treatment (GIST) is a structured cognitive behavioral group intervention addressing social competence after TBI.[3] GIST was developed by two of the investigators (Lenore Hawley and Jody Newman), as a cross-disciplinary, replicable intervention addressing the underlying cognitive, communicative, and emotional impairments impeding social competence after TBI.[3] The intervention combines a psycho-educational curriculum with an interactive group format, emphasizing group feedback and social learning.

GIST was found to be efficacious for individuals with social competency impairment following TBI in a previous single-site study.[20] The objective of the current study was to compare the interactive GIST treatment[3] with an alternative non-interactive treatment through a multi-site study with a diverse sample of civilians and veterans with TBI. Specifically, the study aims were to 1) measure the effectiveness of the GIST intervention with multisite implementation, 2) Explore the potent ingredients associated with the GIST intervention.

\section{METHODS}

\section{DESIGN}

This was a two-arm, multi-center, randomized-controlled clinical trial. This study was approved by the Institutional Review Board at each study site. A computer generated block randomization sequence was used to randomize to either the experimental treatment (GIST) or alternative treatment (AT) in waves of 16 participants at each study center, with each center 
Social Competence Treatment after TBI

104 105

enrolling one to three waves. The outcome data collectors at each site remained blind to study assignment throughout the study.
SETTING

This study was performed at six TBI rehabilitation centers: Craig Hospital; Hunter Holmes McGuire Veterans Affairs Medical Center; University of Washington; Rehabilitation Institute of Michigan; Rehabilitation Hospital of Indiana; and the VA Palo Alto Health Care System.

\section{RECRUITMENT}

Recruitment materials were provided to previous and current patients, local organizations serving individuals with TBI, including state and local brain injury organizations; nearby Veteran's Affairs (VA) centers or veteran organizations; and nearby TBI outpatient clinics. Recruitment took place between August 2012 and August 2014.

\section{INCLUSION/EXCLUSION CRITERIA}

Study inclusion criteria were: history of TBI after October 2001 per the Ohio State University

Traumatic Brain Injury Identification (OSU-TBI-ID) tool [21]; $\geq 6$ months post-injury at enrollment; injury must have occurred after October 2001; $\geq 18$ years old at enrollment; Independent or Overnight Supervision on the Supervision Rating Scale [22]; $\geq 5$ (Supervision) on Comprehension and Expression items of FIM $^{\mathrm{TM}}$ [23]; English speaking; demonstrates problematic social competence on at least one of five screening statements. Participants were asked to report their history of TBI using the OSU-TBI-ID [21] structured interview. The OSU-TBIID is a valid and reliable procedure for eliciting a person's lifetime history of TBI and can be used to categorize severity of self-reported TBI's [21, 24-26]. Further description of type and severity 
Social Competence Treatment after TBI

125

of injury was not captured. Individuals were excluded if they were: unable to verbally communicate; unable to consistently attend treatment sessions; involved in ongoing structured group therapy; or, participating in another intervention trial.

\section{MEASUREMENT}

Enrolled individuals completed a baseline assessment including demographic, injury and cognitive functioning data (Trail Making Test-TMT Part B [27], Rey Auditory Verbal Learning Test-RAVLT [28]), and assessments of social competence skills and emotional well-being as outlined below. Several weeks into treatment participants developed individual social competence goals using the Goal Attainment Scaling (GAS)[29, 30]. At the end of treatment, and at three months post-treatment, participants completed assessments of social competence and emotional well-being.

\section{Social Competence}

The primary outcome measure was a summary score of the Profile of Pragmatic Impairment in Communication (PPIC) [31, 32], an objective, behavioral rating of social communication impairments following TBI. The PPIC has been found to have excellent reliability, convergent validity and discriminant validity in most scales.[33] The PPIC was rated by two blinded trained evaluators (a speech-language pathologist and a social worker) using 10-minute video-recorded conversations of study participants with an unfamiliar conversational partner(site employees not involved in the study and blinded to intervention randomization) at each assessment point. Prior to rating the excerpts, raters were trained (using sample video tapes) by two of the study 
Social Competence Treatment after TBI

145 authors with extensive knowledge of the PPIC until they achieved at least a 0.75 level of

146 reliability on each of the PPIC summary scores among themselves and the trainers.

147 Each PPIC rater assessed each conversational excerpt for this study independently and

148 remained blind to the scoring of the other PPIC rater. An average of the two raters' scores was

149 used for each of the 10 PPIC subscales for each conversational excerpt. As was used in previous

150 research [34], after personal communication with PPIC author [35], the 10 PPIC subscale scores

151 were then added together to create one PPIC summary score to reflect a more comprehensive

152 index of social competence for each conversational excerpt.

153 The 84 behavior items assess frequency and severity of specific communication impairments

154 that fall into 10 subscales (Logical Content, General Participation, Quantity, Quality, Internal

155 Relation, External Relation, Clarity of Expression, Social Style, Subject Matter, and Aesthetics).

156 Each subscale is rated on a Likert-scale of 0 (normal) to 5 (very severely impaired), with lower

157 scores indicating better functional social communication. Videos were randomized, and an

158 average of the two raters' scores was used for each PPIC subscale. The 10 PPIC subscale scores

159 were summed to create a PPIC total score reflecting a comprehensive index of social

160 competence.

161 Self-report assessments of social competence were: the LaTrobe Communication Questionnaire

162 (LCQ),[36] a 30-item self-report measure of cognitive-communication ability in persons with

$163 \mathrm{TBI}$, with scores ranging from 30 to 120 , and higher scores indicating greater communicative

164 impairment; the Scale of Perceived Social Self-Efficacy (PSSE),[37] a 25-item self-report five-

165 point Likert scale of self-efficacy expectations and beliefs regarding social behaviors; the PSSE

166 was modified to exclude two not applicable items, thus total scores ranged from 23 to 115 , with 
Social Competence Treatment after TBI

167

168

169

170

171

172

173

174

175

176

177

178

179

180

181

182

183

184

185

186

187

higher scores indicating greater perceived social self-efficacy. The GAS, a functional outcome measure, (based on a five-point scale, with higher scores indicating greater goal attainment) was used to measure change on individual social competence goals.

\section{Emotional Well-Being}

Measures included: the Satisfaction with Life Scale (SWLS),[38] a Likert-scale measure of global life satisfaction, with raw scores ranging from 5 to 35, and higher scores reflecting greater life satisfaction; the Post Traumatic Stress Disorder Check List-Civilian Version (PCL-C),[39] a Likertscale measure to evaluate symptoms of Post Traumatic Stress Disorder (PTSD), with raw scores ranging from 17 to 85 , and higher scores indicating more PTSD symptomology; and the Brief Symptom Inventory 18 (BSI-18)[40] which measures psychological distress and psychiatric symptoms on three dimensions using T-scores (Somatization, Anxiety, and Depression), and provides an overall measure of psychological distress (Global Severity Index).

\section{INTERVENTION}

GIST is a 13-week program combining a psychoeducational curriculum with an interactive group format, emphasizing group feedback and social learning. Each group consisted of six to eight participants and two therapists. Topics covered include self-assessment, goal setting, starting conversations, conversation strategies, feedback, assertiveness, social problem solving, positive self-talk, social boundaries, and conflict resolution. Session 6 is a group community outing with the therapists to practice goals. The GIST framework parallels Ben-Yishay's Holistic Neuropsychological Rehabilitation Model for TBI, [41] which emphasizes the integration of cognitive remediation with psychotherapeutic interventions in a structured hierarchical 
Social Competence Treatment after TBI

188

approach. GIST sessions occur in a group setting, without supplemental individual sessions.

During each 90 minute group session, key concepts from the previous session are reviewed, a new topic is discussed, strategies and skills are practiced interactively, and real-life social problems are addressed. Therapists encourage the group to interact, share experiences, and give and receive feedback. Each structured treatment topic is presented and discussed within the interactive group conversation.

Group members receive the GIST workbook which includes weekly topics and homework, promoting generalization.. Generalization is specifically targeted through the use of homework, family involvement, use of real-life problem solving, practice in the community, and actual (non-contrived) social interactions during the group sessions. The GIST intervention is described in greater detail elsewhere.[3,42] Treatment dose was defined as the percentage of sessions attended, regardless of the specific sessions attended.

\section{ALTERNATIVE INTERVENTION}

The AT consisted of the GIST curriculum presented in 12 weekly classroom sessions via a powerpoint/audio presentation. One therapist was in the room to provide clarification and answer general questions about the power-point. Each group consisted of six to eight participants and one therapist in the room. GIST treatment activities involving group feedback and interaction were completed individually in AT as pen and paper tasks. Rather than attending a group outing in Session 6, each participant was asked to go on an individual outing (alone, with family, or a friend). Group interaction in the AT was not facilitated but was permitted if it occurred spontaneously. Participants also met individually with a study therapists for 10 minutes each 
Social Competence Treatment after TBI

week for goal setting and monitoring. The fundamental difference from the experimental treatment was the absence of clinician facilitated group dynamics in shaping behavior.

\section{THERAPIST TRAINING}

Two therapists per site facilitated the interventions, a speech-language pathologist with adult TBI experience and a licensed psychotherapist (a clinical social worker or psychologist) with adult TBI and group therapy experience. Two in-person, interactive therapist trainings were provided by the GIST developers [43-45]. One was held prior to the study pilot (overview of therapist study role and the GIST intervention), and the second occurred prior to the main study (AT and review of the goal setting process).

\section{TREATMENT FIDELITY}

An intervention checklist was developed prior to study onset and each session of both treatment conditions was audio-taped to allow assessment of fidelity. The fidelity checklist included both content items to be covered for each session, and specific therapist behaviors, such as giving a prompt to participants to give feedback to others, or encouraging sharing of real-life social skills situations or problems. Feedback was provided to study therapists for sessions not meeting fidelity. Four sessions from each center were observed. Each session had two content items. Raters scored each item exhibited within a session by at least one group therapist. Fidelity was met for the four rated sessions when the pair of group therapists covered seven of the eight content items over the course of the 13 week group. If this occurred, the group therapists were considered to be successfully implementing the content of the program. In addition, ten group process behaviors were observed in four randomized 
Social Competence Treatment after TBI

230

232

233

234

sessions. Eight out of the ten behaviors were required in a single session by at least one of the therapists to have met fidelity for the therapist behavior component.

During the pilot phase, audiotapes from every session at each site were reviewed and feedback was provided to the therapists, through weekly phone conference calls between the therapist pair and the GIST developers. Pilot fidelity was found to be suboptimal for all study sites, with only $17-75 \%$ of sessions reaching fidelity. During the intervention phase, fidelity was again assessed for those sessions where fidelity had not been met during the pilot phase, and for an additional four random sessions for each treatment group. If fidelity was not met for a session, a phone conference took place between the therapists and GIST developers to provide feedback. This fidelity monitoring allowed for the assessment of whether the treatment was delivered as intended.

There was substantial improvement in fidelity during the intervention phase for all centers (wave 1: $60-100 \%$, wave 2: $75-100 \%$, wave 3: $100 \%$ ). Two of the six centers had $100 \%$ fidelity during all waves, and an additional two centers had $100 \%$ fidelity during at least one wave.

\section{STATISTICAL METHODS}

\section{Sample Size and Power Analysis}

The a priori sample size estimation/power analysis (using PASS 2008) indicated a group sample size of 96 (total $n=192$ ) would attain a level of power slightly above $80 \%$ in detecting an effect size of 0.5 (equivalent to detecting a 4-unit difference in the PPIC between treatment arms, assuming a standard deviation of 8), at a significance level of $\alpha=0.05$. 
Social Competence Treatment after TBI

252

253

254

255

256

\section{Statistical Analysis}

All statistical analyses were performed using SAS v.9.4[46]. The mean PPIC total score was modeled over time for each arm using a mixed-effects model with fixed effects for treatment, time, and the treatment by time interaction along with a random center effect to account for center to center variation. Although the random center effect accounted for a small (nonsignificant) percentage of the variations in the outcome (PPIC and secondary outcomes) it was always retained in the models as this is considered standard practice in multi-center studies. A compound symmetry variance-covariance structure was assumed to account for the correlations in the repeated measures over time as it consistently demonstrated significantly better fit than other correlation structures. Changes over time, within and between the treatment arms, were estimated and tested using a Bonferroni correction of $\alpha=0.05 / 9=$ 0.0056. Covariates considered for adjustment were selected a priori and include age, gender, level of education, military status, treatment dose, Trails B (T-scores), RAVLT (Delayed Recall Tscore), and baseline PSSE, LCQ, BSI (T-scores), SWLS, and PCL. The effects of each covariate on PPIC scores were tested and included in the model for adjustment if significant $(\alpha=0.05)$. The relationship between the covariates and outcomes were quantified with mean differences for nominal covariates and slopes for continuous covariates.

The percentage of participants who (a) showed some progress on at least one goal (GAS = 3-5) and (b) achieving at least one goal (GAS $=4-5)$ was computed and compared between the GIST and AT arms at post-treatment and at 3 months post treatment using chi-square tests. 
Social Competence Treatment after TBI

272 The mean responses (LCQ, BSI, PCL, SWLS, and PSSE) were each modeled over time using the

273 same mixed-effects modeling strategy as described for PPIC to determine if changes in the

274 responses over time differed between the arms.

\section{$275 \quad$ RESULTS}

\section{DESCRIPTION OF SAMPLE}

277 Across the six centers, 579 individuals expressed an interest and completed an eligibility screen,

278 of which 179 consented participants met the inclusion criteria and entered randomization

279 (Figure 1 -CONSORT DIAGRAM). The demographic and baseline characteristics by treatment

280 arm are summarized in Table 1. There were not significant differences in these characteristics

281 between arms.

282

\section{PRIMARY ANALYSIS}

The mixed-effects model for total PPIC scores included fixed effects for treatment, time, and

287 for the effects of gender, level of education, Trails B, RAVLT, and baseline PSSE on PPIC scores.

288 The estimated mean PPIC scores from this model are summarized by treatment arm and time in

289 Table 2 and plotted in Figure 2.

290 Overall, there was no significant treatment arm by time interaction $(p=0.2076)$, thus the

291 changes over time in total PPIC scores did not differ significantly between the treatment arms.

292 The estimated changes for each arm and comparisons in the changes between the arms are 
Social Competence Treatment after TBI

293

294

295

296

298

299

300

301

302

303

304

305

306

307

308

309

310

summarized in Table 3. Although the between group interaction effect was not significant,

further secondary analyses were performed to assess for change in PPIC scores between

specific time-points and within each arm (Bonferroni $\alpha=0.0056)$. From baseline to post-

treatment, there were nominal (i.e., non-significant) improvements in total PPIC scores for the

GIST arm (decrease $=1.79$ ) and significant improvements in the AT arm (decrease $=2.66$ ); the improvements did not differ significantly between arms $(p=0.4113)$. There were nominal worsening in total PPIC scores from post-treatment to 3 months post-treatment observed in both arms (GIST increase $=1.18$, AT increase $=0.11$ ); the worsening did not differ significantly between arms ( $p=0.3494)$. From baseline to 3 months post-treatment, PPIC scores in the GIST arm nominally improved by 0.61 , while PPIC scores in the AT arm significantly improved by 2.54; the improvements did not differ significantly between the arms $(p=0.0766)$.

The mixed-effects model also indicated there were a significant effects of gender $(p=0.0045)$ and level of education ( $p=0.0275)$ on PPIC scores and that there were significant negative relationships between total PPIC scores and RAVLT $(p=0.0092)$, Trails B $(p=0.0156)$, and PSSE $(p=0.0121)$. In particular, greater social competence was associated with female gender, having at least a high school level of education, greater memory, greater cognitive speed/flexibility, and greater perceived self-efficacy. Table 4 summarizes the relationship between these covariates and PPIC scores in more detail. 
Social Competence Treatment after TBI

311

312

313

314

315

316

317

318

319

320

321

322

323

324

325

326

327

328

329

330

331

\section{SECONDARY ANALYSES}

\section{Goal Attainment Scale}

Immediately post-treatment, $98.5 \%$ of GIST and $98.1 \%$ of AT participants showed some progress on goals (GAS scores went from 2 to $3-5$ ). Eighty percent of GIST and $82.7 \%$ of AT participants achieved at least one goal (GAS scores 4-5). At three months post-treatment, 95.3\% of GIST and $100 \%$ of AT participants showed some progress on goals, $77.4 \%$ of GIST and $86.0 \%$ of AT participants achieved at least one goal. There were not significant group differences in goal attainment between the arms.

\section{Changes in LCQ, BSI, PCL, SWLS, and PSSE over Time}

Results from the mixed-effects models for BSI, PCL, SWLS, and PSSE are summarized in Tables 2 -4 and plotted in Figure 2. There was no evidence of significant treatment arm by time interaction effects for any of these measures (LCQ: $p=0.2898, \mathrm{BSI}: p=0.2408, \mathrm{PCL}: p=0.1796$, SWLS: $p=0.9854$, and PSSE: $p=0.4677)$; thus changes in each outcome measure over time did not differ between the treatment arms. Post-hoc comparisons adjusting for multiple comparisons indicated that while the AT arm tended to show nominally better improvement in outcomes over time than the GIST arm, the gains were not significantly different between the treatment arms.

\section{Discussion}

The purpose of this study was to test the effectiveness of a manualized social competence group treatment across multiple sites for individuals with chronic TBI living in the community. We hypothesized that this interactive group treatment would be superior to the same content 
Social Competence Treatment after TBI

332

presented through a non-interactive classroom style video presentation with additional brief individual sessions.

After controlling for multiple comparisons, significant improvements in the primary outcome (PPIC) and the two of the secondary outcomes (LCQ and BSI) were seen immediately posttreatment and at 3 months post-treatment in the AT arm only, however these improvements were not significantly different between the treatment arms. Similar trends were observed for PSSE and PCL, except the improvements in PSSE through follow-up were significant in both arms and the improvements in PCL were not maintained through follow-up for either arm. Neither arm showed significant improvements in SWLS over time after controlling for multiple comparisons, although positive trends were noted in both groups.

Participants in both treatment conditions met or exceeded their self-selected functional social competence goals. PPIC, LCQ, BSI, PCL scores tended to stay the same or get worse from posttreatment to 3-months post-treatment, potentially indicating the need for booster sessions, whereas SWLS and PSSE scores continued to improve, perhaps showing a delayed efficacy effect. Given the chronicity of these participants, any positive change on these measures may be clinically meaningful. The study suggests a benefit from the GIST curriculum presented through both the interactive group GIST program and the lecture format which included supplemental individual sessions.

The lack of significant improvement in the GIST arm on the primary outcome contradicts the findings of the prior GIST efficacy clinical trial; however, there were several differences between these studies. A key component of group therapy is group composition, with clinical groups formed based on participant needs and characteristics.[14] Participants in the prior 
Social Competence Treatment after TBI

354

study were more homogeneous in severity of injury, all having a history of moderate to severe

TBI. The current study randomized a wider range of participants, including mild, moderate, and severe injuries, with various levels of physical impairment, as well as veterans and civilians.

In the prior study, each of the 10 PPIC subscale scores were analyzed as opposed to using a sum total score of the 10 PPIC subscales. In addition, the PPIC may not identify the full range of social skills impairments in this more heterogeneous group. In the previous study, the Social Communication Skills Questionnaire (SCSQ)[47] was adapted to capture the spectrum of behaviors addressed by the GIST program that might not be observed through the PPIC. The current study included the LaTrobe Communication Skills Questionnaire due to its wider use within this population.

The prior study involved a wait-list control condition, while the current study included an AT of the GIST curriculum presented in a power-point lecture. While the AT participants did not have facilitated social interaction, they did share this experience together and may have had unmeasured social support in addition to educational presentation of material. In addition, AT participants also received brief individual treatment sessions.

In the prior study, the intervention was provided by the GIST developers, who have years of experience as group therapists and as co-therapists. Group therapist experience has been found to influence therapist/group member dynamics in group therapy.[48] Group therapy is a complex skill-based modality, usually involving significant training and supervision. The GIST intervention is intended to be implemented flexibly, using the clinical experience and judgment of the co-therapists to meet the needs of each group and individual. This level of clinical judgment and adaptation of GIST may require more extensive clinician training than was 
Social Competence Treatment after TBI

provided in this study. It is important to note that the curriculum content provided in the current study resulted in improved goal attainment and scores in both groups. Improvements in personally meaningful, functional goals were found even though those goal behaviors may not have been captured on the ten minute video sample used for the standardized PPIC assessment. The self-selected GAS goals were a focus in both interventions, through individual sessions during the AT and within the group in the GIST treatment.

\section{Limitations}

With the exception of the primary measure, the study relied upon self-report measures. The wide range of participants in this study (mild, moderate, severe, veteran and military) presents a challenge in terms of defining the study sample. The OSU-TBI-ID, a self-report measure, was used to capture history and severity of TBI. Another limitation is that the objective primary measure may not have captured the broad range of social skills addressed in the treatment such as social confidence, increased social activity, or interactions with family. It is possible that the AT was too similar to the treatment condition, using the same curriculum and goal-setting. Additionally, it is possible that the treatment was not fully exported to the study therapists, although efforts were made through training, fidelity checks, and ongoing support. Although group interaction was not intended in the AT, those individuals had the opportunity to interact, share experiences, and develop relationships. In addition, participants may have taken part in other treatment groups and been more likely to spontaneously engage in group interaction. The attendance rates in both groups were low (69\% GIST and 61\% AT) but not unexpected given the nature of group treatment. This could decrease the precision and lower the power to 
Social Competence Treatment after TBI

397

detect clinically important effects.[49] The specific sessions missed by participant were not analyzed in terms of effect on the overall outcome of the participant.

\section{Conclusions}

400 The group interactive format was not found to be a superior method of treatment delivery in

401 this study. However, social competence improved for a heterogeneous group of individuals

402 with chronic TBI in both intervention conditions involving the GIST curriculum. Future research

403

404

405 range of social competence behaviors and skills. The results of this study suggest further

406 investigation of best methods for training multidisciplinary therapists in the complex skills

407 required for group process interventions. 
1. Bellack, A. and M.E. Herson, Research and Practice in Social Skills Training. 1979.

2. Goldfried, M. and T. D'Zurilla, A Behavioral Analytic Model for Assessing Competence, in Current Topics in Clinical and Community Psychology, C. Spielberger, Editor 1969, Academic Press: New York. p. 151-196.

3. Hawley, L. and J. Newman, Group interactive structured treatment (GIST): a social competence intervention for individuals with brain injury. Brain Inj, 2010. 24(11): p. 1292-7.

4. Prigatano, G.P., Work, love, and play after brain injury. Bull Menninger Clin, 1989. 53(5): p. 414-31.

5. Sale, P., et al., Exploratory analysis of job separations from supported employment for persons with traumatic brain injury. Journal of Head Trauma Rehabilitation, 1991. 6: p. 1-11.

6. Ezrachi, O., et al., Predicting employment in traumatic brain injury following neuropsychological rehabilitation. Journal of Head Trauma Rehabilitation, 1991. 6: p. 71-84.

7. Wehman, P., et al., Critical factors associated with the successful supported employment placement of patients with severe traumatic brain injury. Brain Injury, 1993. 7(1): p. 31-44.

8. Tate, R.L., et al., Psychosocial outcome for the survivors of severe blunt head injury: the results from a consecutive series of 100 patients. J Neurol Neurosurg Psychiatry, 1989. 52(10): p. 1128-34.

9. Blais, M.C. and J.M. Boisvert, Psychological and marital adjustment in couples following a traumatic brain injury (TBI): a critical review. Brain Inj, 2005. 19(14): p. 1223-35.

10. Hoofien, D., et al., Traumatic brain injury (TBI) 10-20 years later: a comprehensive outcome study of psychiatric symptomatology, cognitive abilities and psychosocial functioning. Brain Inj, 2001. 15(3): p. 189-209.

11. Galski, T., C. Tompkins, and M.V. Johnston, Competence in discourse as a measure of social integration and quality of life in persons with traumatic brain injury. Brain Inj, 1998. 12(9): p. 769-82.

12. McDonald, S. and S. Flanagan, Social perception deficits after traumatic brain injury: interaction between emotion recognition, mentalizing ability, and social communication. Neuropsychology, 2004. 18(3): p. 572-9.

13. Bellack, A. and E. Hersen M, Research and Practice in Social Skills Training. 1979.

14. Yalom ID and Leszcz M, Theory and Practice of Group Psychotherapy. 5th ed2005, New York,: Basic Books.

15. Rose, S., Group Therapy with Troubled Youth1998, Thousand Oaks CA: Sage Publishing.

16. Howe, L.L., Giving context to post-deployment post-concussive-like symptoms: blastrelated potential mild traumatic brain injury and comorbidities. Clin Neuropsychol, 2009. 23(8): p. 1315-37. 
Social Competence Treatment after TBI

17. Hoge, C.W., et al., Mild traumatic brain injury in U.S. Soldiers returning from Iraq. $\mathbf{N}$ Engl J Med, 2008. 358(5): p. 453-63.

18. Hawley, L., Newman J., Group Interactive Structured Treatment - GIST2008, Denver.

19. McDonald, S., et al., Social skills treatment for people with severe, chronic acquired brain injuries: a multicenter trial. Arch Phys Med Rehabil, 2008. 89(9): p. 1648-59.

20. Dahlberg, C.A., et al., Treatment efficacy of social communication skills training after traumatic brain injury: a randomized treatment and deferred treatment controlled trial. Arch Phys Med Rehabil, 2007. 88(12): p. 1561-73.

21. Corrigan, J.D. and J. Bogner, Initial reliability and validity of the Ohio State University TBI Identification Method. J Head Trauma Rehabil, 2007. 22(6): p. 318-29.

22. Boake, C., Supervision rating scale: a measure of functional outcome from brain injury. Arch Phys Med Rehabil, 1996. 77(8): p. 765-72.

23. Guide for the Uniform Data Set for Medical Rehabilitation (including the FIM (TM) instrument), Version 5.11997, Buffalo, NY: State University of New York at Buffalo.

24. Bogner, J. and J.D. Corrigan, Reliability and predictive validity of the Ohio State University TBI identification method with prisoners. J Head Trauma Rehabil, 2009. 24(4): p. 279-91.

25. Fortier, C.B., et al., The Boston Assessment of Traumatic Brain Injury-Lifetime (BAT-L) semistructured interview: evidence of research utility and validity. J Head Trauma Rehabil, 2014. 29(1): p. 89-98.

26. Brenner, L.A., et al., Prevalence and screening of traumatic brain injury among veterans seeking mental health services. J Head Trauma Rehabil, 2013. 28(1): p. 21-30.

27. Reitan, R., 1986 Reitan Neuropsychological Laboratory

28. Schmidt, M., Rey Auditory Verbal Learning Test: a handbook 2010 Western Psychological Services

29. Kiresuk, T.J., A. Smith, and J.E. Cardillo, eds. Goal Attainment Scaling: Applications, Theory, and Measurement. 1994, Lawrence Erlbaum Associates: New Jersey.

30. Malec, J., J. Smigielski, and R. DePompolo, Goal Attainment Scaling and Outcome Measurement in Postacute Brain injury Rehabilitation. Arch Phys Med Rehabil, 1991. 72: p. 138-143.

31. Hays, S.J., et al., Clinical assessment of pragmatic language impairment: $A$ generalisability study of older people with Alzheimer's disease. Aphasiology, 2004. 18(8): p. 693-714.

32. Linscott, R.J., R.G. Knight, and H.P. Godfrey, The Profile of Functional Impairment in Communication (PFIC): a measure of communication impairment for clinical use. Brain Inj, 1996. 10(6): p. 397-412.

33. Hays SJ, N.B., Godfrey HPD, Linscott RJ, Clinical assessment of pragmatic language impairment: a generalizability study of older people with Alzheimer's disease. Aphasiology, 2004. 18: p. 693-714.

34. Braden, C., et al., Social communication skills group treatment: A feasibility study for persons with traumatic brain injury and comorbid conditions. Brain Injury, 2010. 24(11): p. 1298-1310.

35. Linscott, R., Personal Communication, 2010. 
36. Douglas, J.M., C.A. Bracy, and P.C. Snow, Measuring perceived communicative ability after traumatic brain injury: reliability and validity of the La Trobe Communication Questionnaire. J Head Trauma Rehabil, 2007. 22(1): p. 31-8.

37. Smith, H. and N. Betz, Development and Validation of a Scale of Perceived Social SelfEfficacy. Journal of Career Assessment 2000. 8(3): p. 283-301.

38. Diener, E., et al., The Satisfaction With Life Scale. J Personality Assessment, 1985. 49: p. 71-75.

39. Weathers, L. and L. Huska. Post Traumatic Stress Checklist - Civilian Version. September 1, 2010]; Available from:

http://www.pdhealth.mil/guidelines/appendix3.asp.

40. Derogatis, L., Brief Symptom Inventory 18, 2001, NCS Pearson, Inc.: Minneapolis.

41. Ben-Yishay, Y., Neurospsychological Rehabilitation: Quest for Holistic Approach. Seminars in Neurology, 1985. 5(3:252).

42. Hawley, L. and J. Newman, eds. Social skills and traumatic brain injury: a workbook for group treatment. 2006: Denver, CO.

43. Siqueland, L., et al., The role of therapist characteristics in training effects in cognitive, supportive-expressive, and drug counseling therapies for cocaine dependence. $J$ Psychother Pract Res, 2000. 9(3): p. 123-30.

44. Santacroce, S.J., L.M. Maccarelli, and M. Grey, Intervention fidelity. Nurs Res, 2004. 53(1): p. 63-6.

45. Sanchez, V., et al., Fidelity of implementation in a treatment effectiveness trial of Reconnecting Youth. Health Educ Res, 2007. 22(1): p. 95-107.

46. SAS System for Mixed Models, R. Littel, et al., Editors.

47. McGann, W., G. Werven, and M. Douglas, Social competence and head injury: a practical approach. Brain Injury, 1997. 11(9): p. 621-628.

48. MacNair-Semands, R., Predicitng Attendance and Expectations for Group Therapy. Group Dynamics: Theory, Research, and Practice, 2002. 6(3): p. 219-228.

49. Bell, K., et al., Participant Recruitment and Retention in Rehabilitation Research. American Journal of Physical Medicine in Rehabilitation, 2008. 87: p. 330-338. 
Table 1: Demographic and Baseline Characteristics

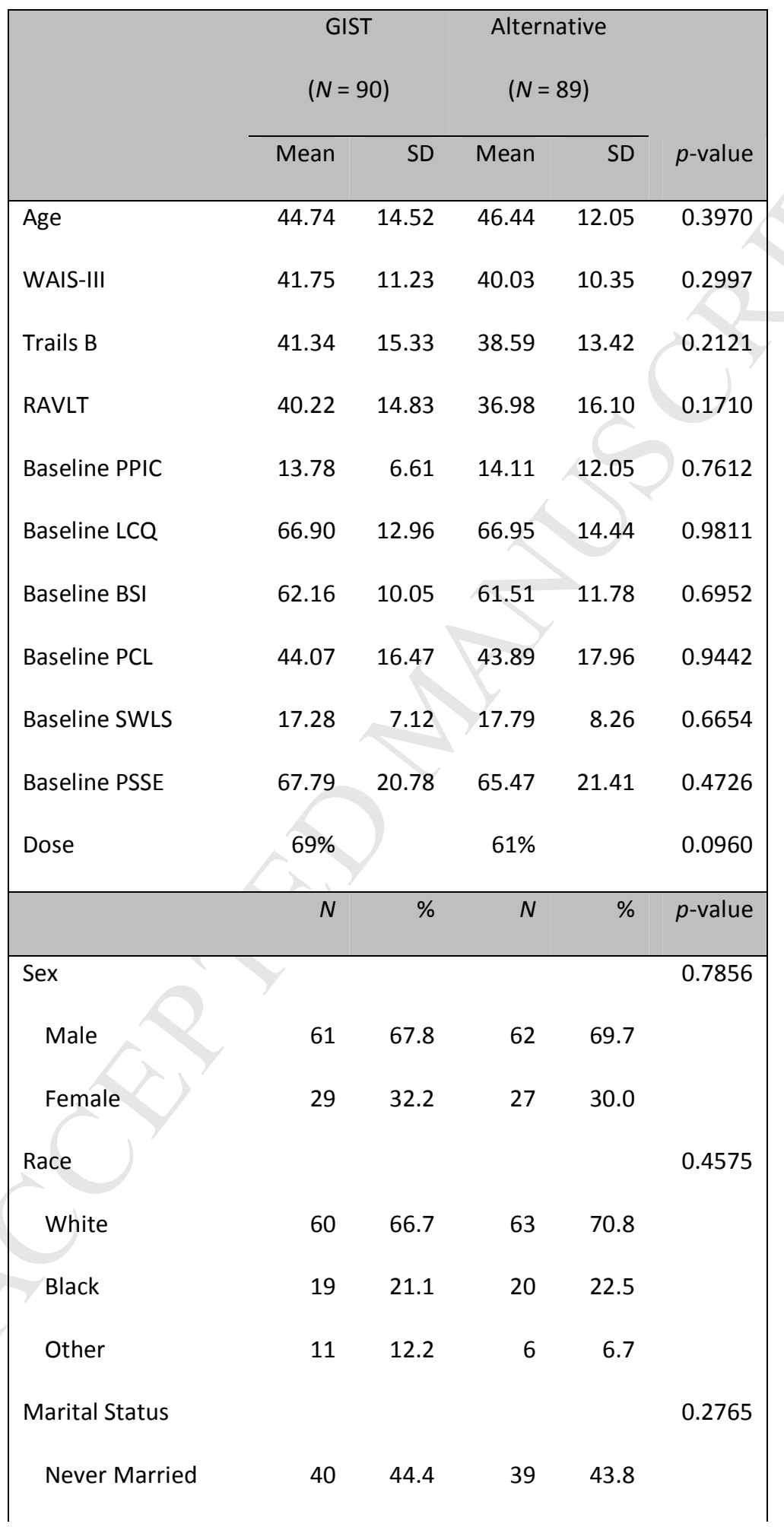




\begin{tabular}{|c|c|c|c|c|c|}
\hline Married & 28 & 31.1 & 20 & 22.5 & \\
\hline Other & 22 & 24.4 & 30 & 33.7 & \\
\hline Education Level & & & & & 0.9043 \\
\hline$<$ High School & 9 & 10.0 & 9 & 10.1 & \\
\hline High School/GED & 28 & 31.1 & 25 & 28.1 & \\
\hline > High School & 53 & 58.9 & 55 & 61.8 & \\
\hline Current & & & & & 0.23 \\
\hline \multicolumn{6}{|l|}{ Employment } \\
\hline Employed & 27 & 30.3 & 20 & 22.5 & \\
\hline Unemployed & 62 & 69.7 & 69 & 77.5 & \\
\hline Military Status & & & & & 0.4836 \\
\hline Civilian & 65 & 72.2 & 60 & 67.4 & \\
\hline Military & 25 & 27.8 & 29 & 32.6 & \\
\hline OSU & & & & & 0.6430 \\
\hline Mild TBI LOC - & 11 & 12.8 & 18 & 20.2 & \\
\hline Mild TBI LOC + & 31 & 36.0 & 28 & 31.5 & \\
\hline Moderate & 14 & 16.3 & 11 & 12.4 & \\
\hline Severe TBI & 27 & 31.4 & 30 & 33.7 & \\
\hline Unknown TBI & 3 & 3.5 & 2 & 2.2 & \\
\hline MSVT II & & & & & 0.7045 \\
\hline Valid & 56 & 65.9 & 59 & 68.6 & \\
\hline Invalid & 29 & 34.1 & 27 & 31.4 & \\
\hline
\end{tabular}


Social Competence Training after TBI

Table 2: Estimated Mean Response Scores by Group and Time

\begin{tabular}{|c|c|c|c|c|}
\hline Treatment & Time & LS Mean & SE & $95 \% \mathrm{Cl}$ \\
\hline \multicolumn{5}{|c|}{ PPIC: Functional Social Communication } \\
\hline \multirow[t]{3}{*}{ GIST } & Baseline & 13.86 & 0.91 & $(12.02,15.70)$ \\
\hline & Post-Treatment & 12.07 & 0.98 & $(10.10,14.04)$ \\
\hline & 3 Months Post-Treatment & 13.25 & 0.98 & $(11.27,15.24)$ \\
\hline \multirow[t]{3}{*}{ Alternative } & Baseline & 13.51 & 0.90 & $(11.69,15.33)$ \\
\hline & Post-Treatment & 10.85 & 0.97 & $(8.90,12.81)$ \\
\hline & 3 Months Post-Treatment & 10.96 & 1.00 & $(8.96,13.0)$ \\
\hline \multicolumn{5}{|c|}{ LCQ: Communicative Impairment } \\
\hline \multirow[t]{3}{*}{ GIST } & Baseline & 66.42 & 1.01 & $(64.44,68.40)$ \\
\hline & Post-Treatment & 62.79 & 1.12 & $(60.59,64.99)$ \\
\hline & 3 Months Post-Treatment & 63.20 & 1.12 & $(61.00,65.40)$ \\
\hline \multirow[t]{3}{*}{ Alternative } & Baseline & 66.94 & 0.99 & $(64.44,64.99)$ \\
\hline & Post-Treatment & 60.69 & 1.19 & $(58.36,63.02)$ \\
\hline & 3 Months Post-Treatment & 61.80 & 1.18 & $(59.50,64.09)$ \\
\hline \multicolumn{5}{|c|}{ BSI: Psychological Distress } \\
\hline \multirow[t]{3}{*}{ GIST } & Baseline & 61.83 & 0.85 & $(60.08,63.58)$ \\
\hline & Post-Treatment & 60.57 & 0.94 & $(58.66,62.47)$ \\
\hline & 3 Months Post-Treatment & 60.95 & 0.96 & $(59.02,62.88)$ \\
\hline \multirow{3}{*}{ Alternative } & Baseline & 61.11 & 0.83 & $(59.41,62.82)$ \\
\hline & Post-Treatment & 57.85 & 0.96 & $(55.92,59.79)$ \\
\hline & 3 Months Post-Treatment & 58.31 & 0.97 & $(56.35,60.26)$ \\
\hline \multicolumn{5}{|c|}{ PCL: PTSD Symptomology } \\
\hline GIST & Baseline & 44.42 & 1.61 & $(40.87,47.96)$ \\
\hline
\end{tabular}


Social Competence Training after TBI

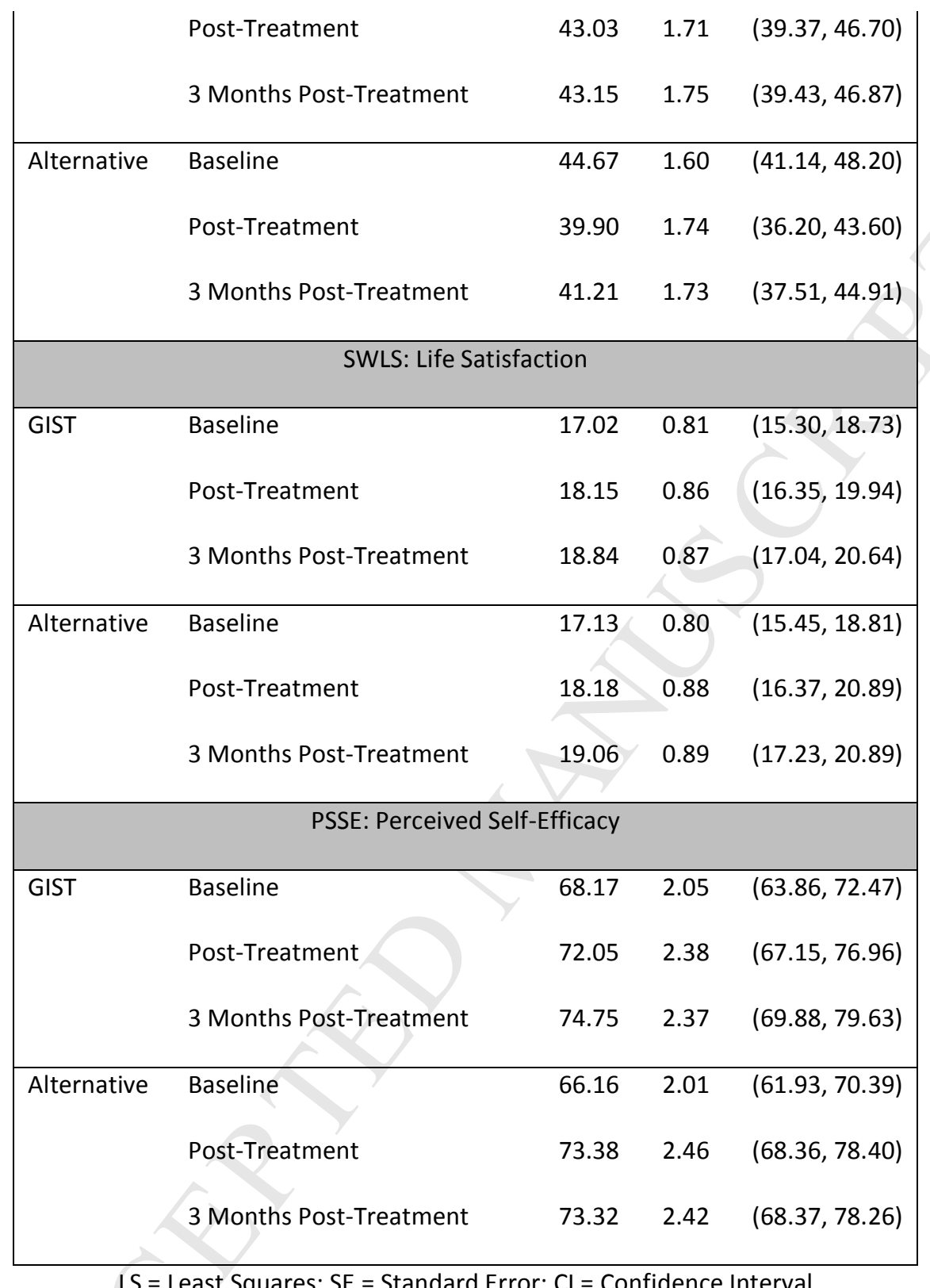


Table 3: Estimated Changes in Response Measures over Time by Group and Comparisons in the Changes between the Groups

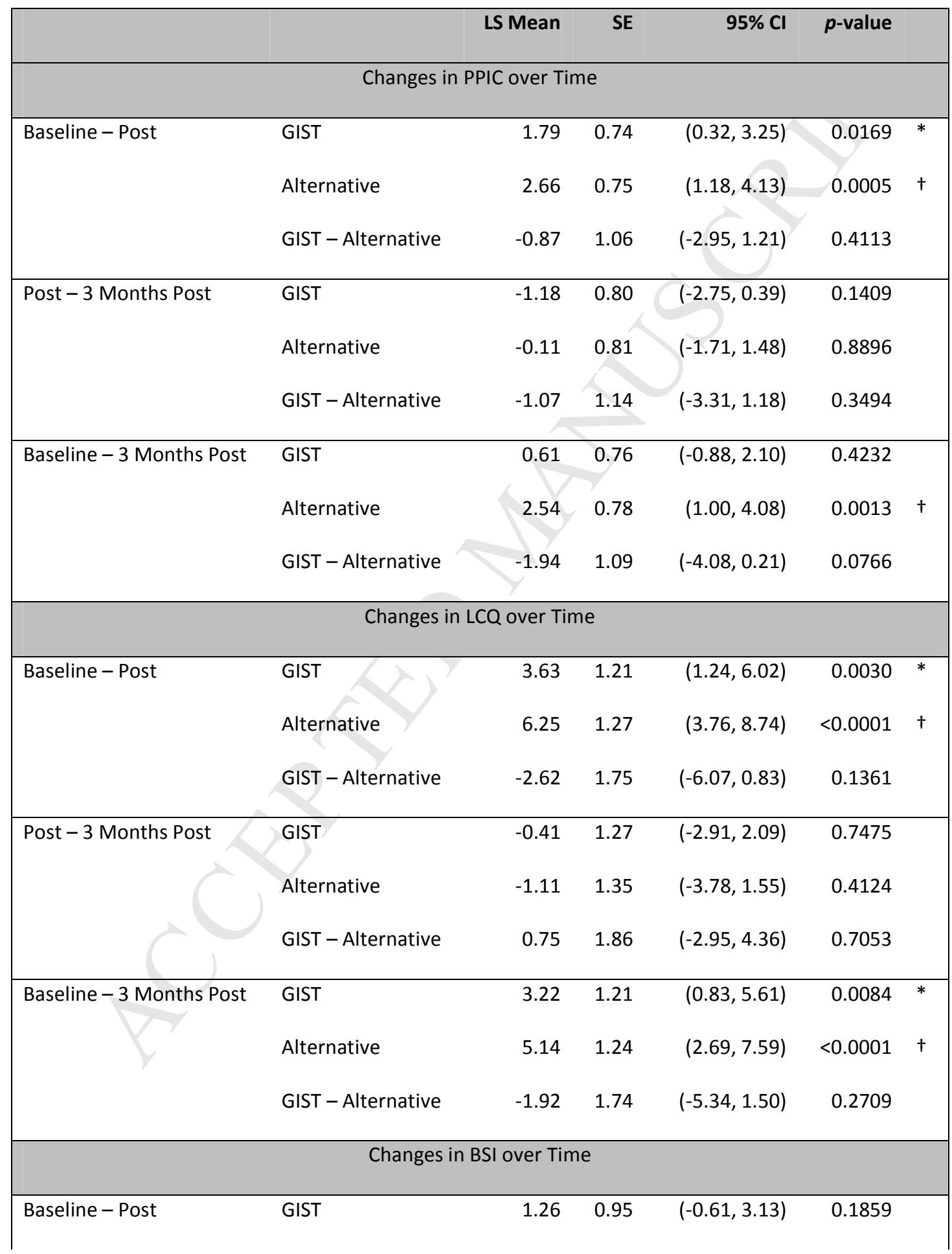




\begin{tabular}{|c|c|c|c|c|c|c|}
\hline & Alternative & 3.26 & 0.97 & $(1.35,5.17)$ & 0.0009 & \multirow[t]{2}{*}{+} \\
\hline & GIST - Alternative & -2.00 & 1.36 & $(-4.67,0.67)$ & 0.1423 & \\
\hline \multirow[t]{3}{*}{ Post - 3 Months Post } & GIST & -0.38 & 1.01 & $(-2.36,1.60)$ & 0.7049 & \\
\hline & Alternative & -0.45 & 1.04 & $(-2.50,1.59)$ & 0.6637 & \\
\hline & GIST - Alternative & 0.07 & 1.45 & $(-2.78,2.92)$ & 0.9612 & \\
\hline \multirow[t]{3}{*}{ Baseline - 3 Months Post } & GIST & 0.88 & 0.97 & $(-1.02,2.78)$ & 0.3639 & \multirow{3}{*}{$\dagger$} \\
\hline & IST & 2.81 & 0.98 & $(0.87,4.74)$ & 0.0046 & \\
\hline & GIST - IST & -1.93 & 1.38 & $(-4.64,0.79)$ & 0.1632 & \\
\hline \multicolumn{7}{|c|}{ Changes in PCL over Time } \\
\hline \multirow[t]{3}{*}{ Baseline - Post } & GIST & 1.38 & 1.31 & $(-1.19,3.95)$ & 0.2913 & \multirow{3}{*}{$\dagger$} \\
\hline & Alternative & 4.77 & 1.35 & $(2.11,7.43)$ & 0.0005 & \\
\hline & GIST - Alternative & -3.39 & 1.87 & $(-7.06,0.29)$ & 0.0709 & \\
\hline \multirow[t]{3}{*}{ Post -3 Months Post } & GIST & -0.11 & 1.42 & $(-2.92,2.69)$ & 0.9366 & \multirow{6}{*}{ * } \\
\hline & Alternative & -1.31 & 1.43 & $(-4.12,1.50)$ & 0.3588 & \\
\hline & GIST - Alternati & 1.20 & 2.02 & $(-2.77,5.17)$ & 0.5529 & \\
\hline \multirow[t]{3}{*}{ Baseline -3 Months Post } & GIST & 1.27 & 1.36 & $(-1.42,3.96)$ & 0.3537 & \\
\hline & Alternative & 3.46 & 1.34 & $(0.82,6.10)$ & 0.0105 & \\
\hline & GIST - Alternative & -2.19 & 1.90 & $(-5.94,1.56)$ & 0.2515 & \\
\hline \multicolumn{7}{|c|}{ Changes in SWLS over Time } \\
\hline \multirow[t]{3}{*}{ Baseline - Post } & GIST & -1.13 & 0.70 & $(-2.51,0.25)$ & 0.1089 & \\
\hline & Alternative & -1.05 & 0.73 & $(-2.49,0.39)$ & 0.1526 & \\
\hline & GIST - Alternative & -0.08 & 1.01 & $(-2.08,1.91)$ & 0.9353 & \\
\hline \multirow[t]{3}{*}{ Post - 3 Months Post } & GIST & -0.70 & 0.73 & $(-2.14,0.74)$ & 0.3412 & \\
\hline & Alternative & -0.88 & 0.77 & $(-2.40,0.64)$ & 0.2563 & \\
\hline & GIST - Alternative & 0.18 & 1.07 & $(-1.92,2.28)$ & 0.8643 & \\
\hline Baseline -3 Months Post & GIST & -1.83 & 0.71 & $(-3.23,-0.43)$ & 0.0107 & $*$ \\
\hline
\end{tabular}




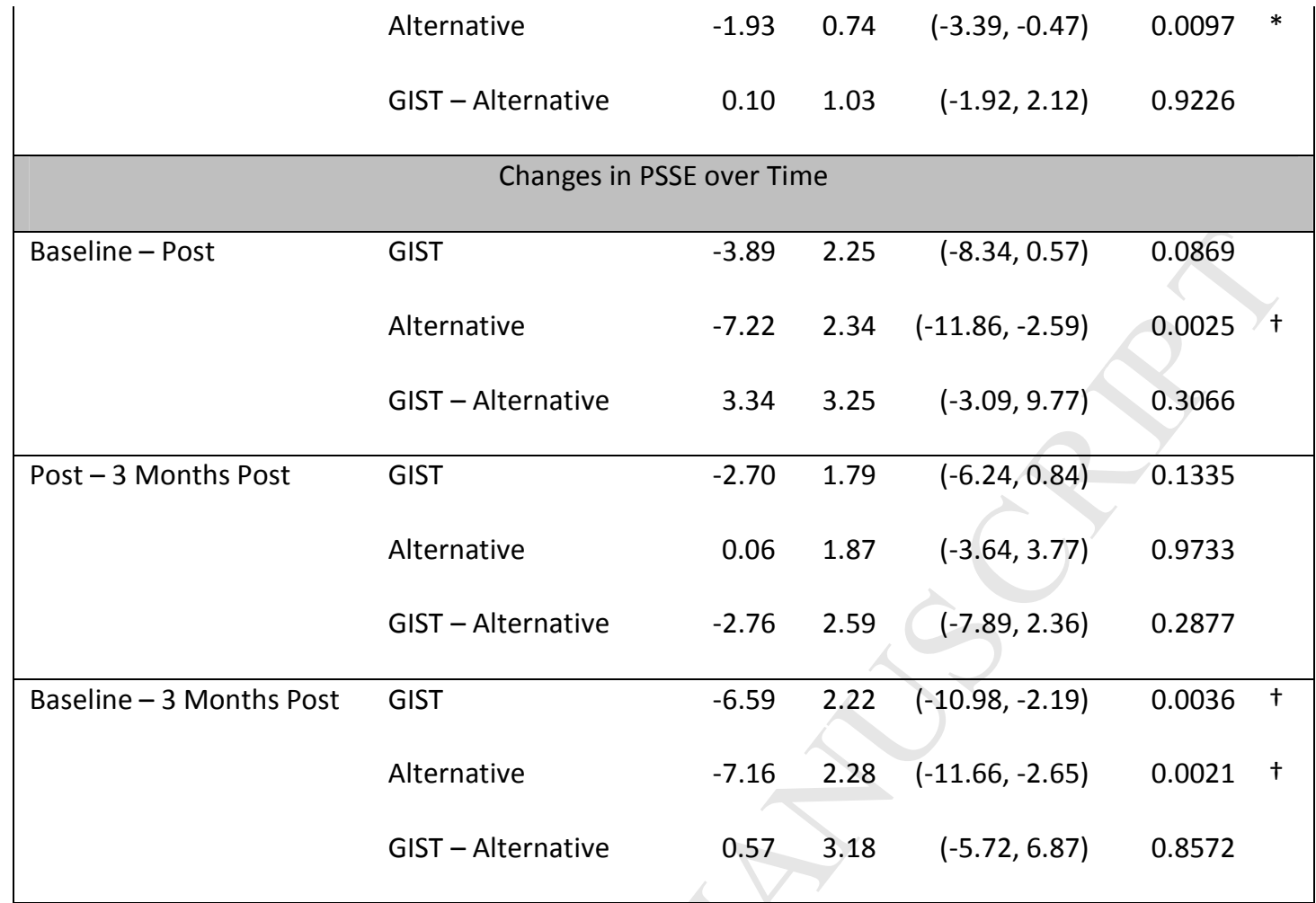

LS = Least Squares; SE = Standard Error; $\mathrm{Cl}$ = Confidence Interval

* = Statistically significant without adjusting for multiple comparisons $(\alpha=0.05)$

$\dagger=$ Statistically significant after adjusting for multiple comparisons $(\alpha=0.05 / 9=0.0056)$ 
Table 4: Relationship between Covariates and Response Measures

\begin{tabular}{|c|c|c|c|}
\hline Result & Relationship to PPIC & SE & $95 \% \mathrm{Cl}$ \\
\hline $\begin{array}{l}\text { Females had greater social competence than } \\
\text { males. }\end{array}$ & $\begin{array}{l}\text { Females had lower PPIC scores than males } \\
\text { by } 2.844 \text { units. }\end{array}$ & 0.986 & $0.895,4.793)$ \\
\hline $\begin{array}{l}\text { Participants with at least a High School level of } \\
\text { education had greater social competence than } \\
\text { those with less than a High School level of } \\
\text { education }\end{array}$ & $\begin{array}{l}\text { High School level had lower PPIC than less } \\
\text { than High School level by } 3.625 \text { units. } \\
\text { More than High School level had lower } \\
\text { PPIC than less than High School level by } \\
4.464 \text { units. }\end{array}$ & $\begin{array}{r}1.757 \\
1.655\end{array}$ & $(0.149,7.101)$ \\
\hline $\begin{array}{l}\text { Greater memory was associated with greater } \\
\text { social competence. }\end{array}$ & $\begin{array}{l}\text { A one unit increase in RAVLT scores was } \\
\text { associated with a } 0.065 \text { unit decrease in } \\
\text { PPIC scores. }\end{array}$ & 0.030 & $(0.005,0.125)$ \\
\hline $\begin{array}{l}\text { Greater cognitive speed/flexibility (less } \\
\text { cognitive impairment) was associated with } \\
\text { greater social competence. }\end{array}$ & $\begin{array}{l}\text { A one unit increase in Trails B scores was } \\
\text { associated with a } 0.092 \text { unit decrease in } \\
\text { PPIC scores. }\end{array}$ & 0.033 & $(0.026,0.157)$ \\
\hline $\begin{array}{l}\text { Greater perceived self-efficacy was associated } \\
\text { with greater social competence. }\end{array}$ & $\begin{array}{l}\text { A one unit increase in baseline PSSE scores } \\
\text { was associated with a } 0.064 \text { unit decrease } \\
\text { in PPIC scores. }\end{array}$ & 0.022 & $(0.020,0.108)$ \\
\hline Result & Relationship to LCQ & SE & $95 \% \mathrm{Cl}$ \\
\hline $\begin{array}{l}\text { Greater perceived self-efficacy was associated } \\
\text { with less communicative impairment. }\end{array}$ & $\begin{array}{l}\text { A one unit increase in baseline PSSE scores } \\
\text { was associated with a } 0.113 \text { unit decrease } \\
\text { in LCQ scores. }\end{array}$ & 0.030 & $(0.053,0.172)$ \\
\hline $\begin{array}{l}\text { Greater psychological distress was associated } \\
\text { with greater communicative impairment. }\end{array}$ & $\begin{array}{l}\text { A one unit increase in baseline BSI scores } \\
\text { was associated with a } 0462 \text { unit increase in } \\
\text { LCQ scores. }\end{array}$ & 0.087 & $(0.290,0.663)$ \\
\hline
\end{tabular}




\begin{tabular}{|c|c|c|c|}
\hline $\begin{array}{l}\text { Greater PTSD symptomology was associated } \\
\text { with greater communicative impairment. }\end{array}$ & $\begin{array}{l}\text { A one unit increase in baseline PCL scores } \\
\text { was associated with a } 0.217 \text { unit increase } \\
\text { in LCQ scores. }\end{array}$ & 0.055 & $(0.108,0.327)$ \\
\hline Result & Relationship to BSI & SE & $95 \% \mathrm{Cl}$ \\
\hline $\begin{array}{l}\text { Greater life satisfaction was associated with } \\
\text { less psychological distress. }\end{array}$ & $\begin{array}{l}\text { A one unit increase in baseline SWLS was } \\
\text { associated with a } 0.141 \text { unit decrease in BSI } \\
\text { scores. }\end{array}$ & 0.067 & $(0.009,0.274)$ \\
\hline $\begin{array}{l}\text { Greater PTSD symptomology was associated } \\
\text { with greater psychological distress. }\end{array}$ & $\begin{array}{l}\text { A one unit increase in baseline PCL was } \\
\text { associated with a } 0.359 \text { unit increase in BSI } \\
\text { scores. }\end{array}$ & 0.038 & $(0.284,0.435)$ \\
\hline $\begin{array}{l}\text { Greater communicative impairment was } \\
\text { associated with greater psychological distress. }\end{array}$ & $\begin{array}{l}\text { A one unit increase in baseline LCQ was } \\
\text { associated with a } 0.188 \text { unit increase in BSI } \\
\text { scores. }\end{array}$ & 0.046 & $(0.098,0.278)$ \\
\hline Result & Relationship to $\mathrm{PCL}$ & SE & $95 \% \mathrm{Cl}$ \\
\hline $\begin{array}{l}\text { Adequate effort was associated with less PTSD } \\
\text { symptomology. }\end{array}$ & $\begin{array}{l}\text { Those who scored invalid on MSVT II had } \\
\text { higher PCL scores by } 4.116 \text { than those who } \\
\text { scored valid. }\end{array}$ & 1.598 & $(0.962,7.271)$ \\
\hline $\begin{array}{l}\text { More treatment (dose) was associated with } \\
\text { less PTSD symptomology. }\end{array}$ & $\begin{array}{l}\text { A one unit increase in dose was associated } \\
\text { with a } 7.803 \text { unit decrease in PCL scores. }\end{array}$ & 2.422 & $(3.027,7.271)$ \\
\hline $\begin{array}{l}\text { Greater psychological distress was associated } \\
\text { with greater PTSD symptomology. }\end{array}$ & $\begin{array}{l}\text { A one unit increase in baseline BSI scores } \\
\text { was associated with a } 0.959 \text { unit increase } \\
\text { in PCL scores. }\end{array}$ & 0.090 & $(0.781,1.138)$ \\
\hline $\begin{array}{l}\text { Greater communicative impairment was } \\
\text { associated with greater PTSD symptomology. }\end{array}$ & $\begin{array}{l}\text { A one unit increase in baseline LCQ scores } \\
\text { was associated with a } 0.202 \text { unit increase } \\
\text { in PCL scores. }\end{array}$ & 0.073 & $(0.057,0.347)$ \\
\hline Result & Relationship to SWLS & SE & $95 \% \mathrm{Cl}$ \\
\hline
\end{tabular}




\begin{tabular}{|c|c|c|c|}
\hline $\begin{array}{l}\text { Adequate effort was associated with greater } \\
\text { life satisfaction. }\end{array}$ & $\begin{array}{l}\text { Those who scored invalid on MSVT II had } \\
\text { lower SWLS scores by } 2.810 \text { than those } \\
\text { who scored valid. }\end{array}$ & 1.092 & $(0.653,4.968)$ \\
\hline $\begin{array}{l}\text { Greater psychological distress was associated } \\
\text { with less life satisfaction. }\end{array}$ & $\begin{array}{l}\text { A one unit increase in baseline BSI scores } \\
\text { was associated with a } 0.213 \text { unit decrease } \\
\text { in SWLS scores. }\end{array}$ & 0.049 & $(0.115,0.310)$ \\
\hline $\begin{array}{l}\text { Greater perceived self-efficacy was associated } \\
\text { with greater life satisfaction. }\end{array}$ & $\begin{array}{l}\text { A one unit increase in baseline PSSE scores } \\
\text { was associated with a } 0.095 \text { unit increase } \\
\text { in SWLS scores. }\end{array}$ & 0.026 & $(0.044,0.146)$ \\
\hline Result & Relationship to PSSE & SE & $95 \% \mathrm{Cl}$ \\
\hline $\begin{array}{l}\text { Greater communicative impairment was } \\
\text { associated with less perceived self-efficacy. }\end{array}$ & $\begin{array}{l}\text { A one unit increase in baseline LCQ scores } \\
\text { was associated with a } 0.649 \text { unit decrease } \\
\text { in PSSE scores. }\end{array}$ & 0.095 & $(0.462,0.837)$ \\
\hline $\begin{array}{l}\text { Greater functional social competence was } \\
\text { associated with greater perceived self- } \\
\text { efficacy. }\end{array}$ & $\begin{array}{l}\text { A one unit decrease in baseline PPIC scores } \\
\text { was associated with a } 0.723 \text { unit increase } \\
\text { in PSSE scores. }\end{array}$ & 0.170 & $(0.388,1.058)$ \\
\hline $\begin{array}{l}\text { Greater life satisfaction was associated with } \\
\text { greater perceived self-efficacy. }\end{array}$ & $\begin{array}{l}\text { A one unit increase in baseline SWLS scores } \\
\text { was associated with a } 0.563 \text { unit increase } \\
\text { in PSSE scores. }\end{array}$ & 0.160 & $(0.247,0.879)$ \\
\hline
\end{tabular}




\section{Figure 1 - Consort Diagram}

\section{ENROLLMENT}

Assessed for eligibility $(n=578)$

Excluded ( $n=399$ )

- Not meeting inclusion criteria $(n=318)$

- Declined to participate $(n=81)$

\section{TREATMENT}

Allocated to GIST intervention ( $n=90$ )

Completed Baseline Assessment $(n=90)$
Randomized ( $n=179)$

\begin{tabular}{|c|c|c|}
\hline$\downarrow$ & ALLOCATION & $\downarrow$ \\
\hline $\begin{array}{l}\text { TREATMENT } \\
\text { Allocated to GIST intervention }(n=90) \\
\text { Completed Baseline Assessment }(n=90)\end{array}$ & \multirow[b]{2}{*}{ INTERVENTION } & $\begin{array}{l}\text { CONTROL } \\
\text { Allocated to alternative intervention }(n=89) \\
\text { Completed Baseline Assessment }(n=88)\end{array}$ \\
\hline$\downarrow$ & & \multirow{2}{*}{$\begin{array}{l}\text { Received at least some of the allocated } \\
\text { intervention }(n=82) \\
\text { Did not receive intervention/drop out prior to } \\
\text { attending any alternative intervention } \\
\text { sessions }(n=7)\end{array}$} \\
\hline $\begin{array}{l}\text { - Received at least some of the allocated } \\
\text { intervention }(n=86) \\
\text { - Did not receive intervention/drop out prior to } \\
\text { attending any GIST sessions }(n=4)\end{array}$ & & \\
\hline$\alpha$ & POST TX & $\downarrow$ \\
\hline $\begin{array}{l}\text { Primary analysis of primary outcome }(n=64) \\
\text { Excluded from analysis }(n=26) \\
\text { - Did not receive intervention }(n=4) \\
\text { - Lost to follow-up }(n=22)\end{array}$ & & $\begin{array}{l}\text { Primary analysis of primary outcome }(n=61) \\
\text { Excluded from analysis }(n=28) \\
\text { - Did not receive intervention }(n=7) \\
\text { - Lost to follow-up }(n=21)\end{array}$ \\
\hline
\end{tabular}

\section{MONTH}

Primary analysis of primary outcome $(n=61)$

Excluded from analysis $(n=29)$

- Did not receive intervention $(n=4)$

- Lost to follow-up ( $n=25)$
Primary analysis of primary outcome $(n=55)$

Excluded from analysis $(n=34)$

- Did not receive intervention $(n=7)$

- Lost to follow-up ( $n=27)$ 
Figure 2: Mean Response Variables over Time by Group with 95\% Confidence Intervals
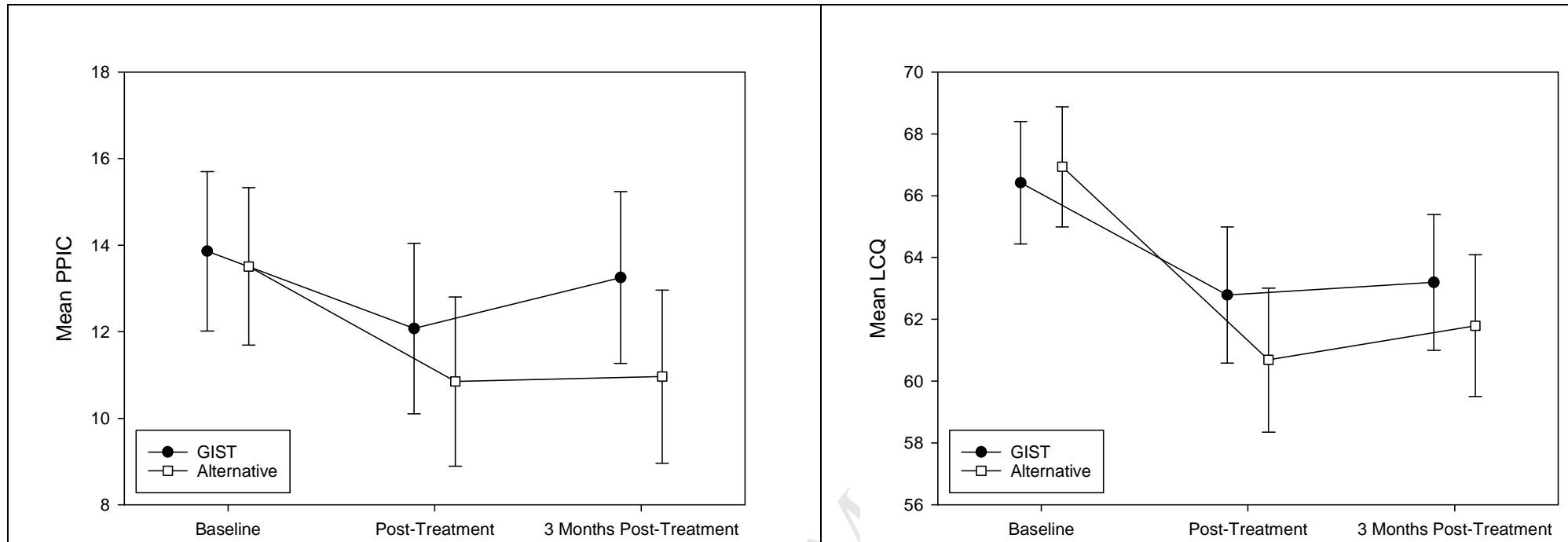

PPIC: Lower scores indicate improved social competence

LCQ: Lower scores indicate improved communication





PCL: Lower scores indicate reduced PTSD symptomology

SWLS: Higher scores indicate improved life satisfaction

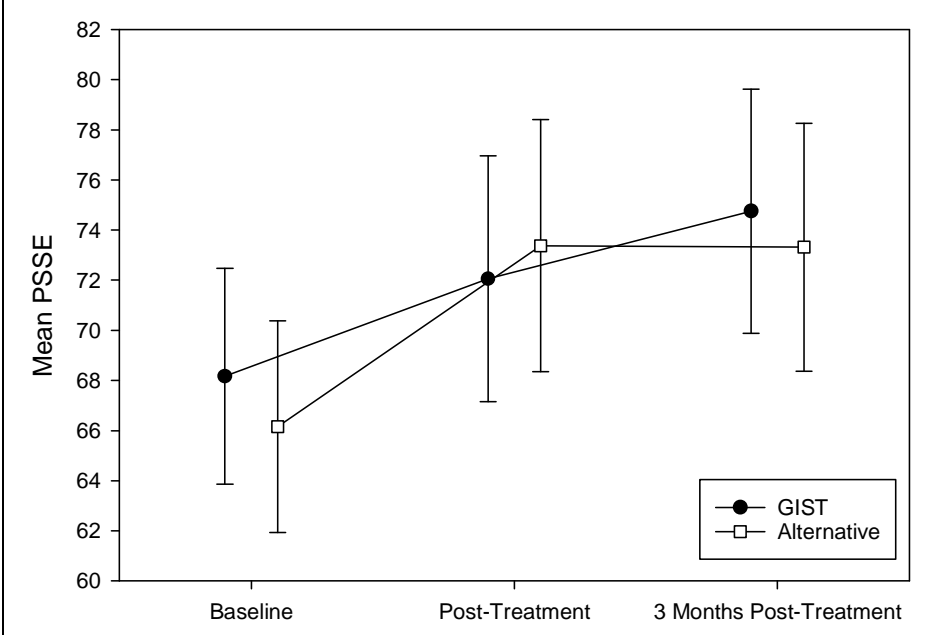

PSSE: Higher scores indicate improved self-efficacy 